\title{
The influence of the circulation on surface temperature and precipitation patterns over Europe
}

\author{
P. D. Jones* and D. H. Lister \\ Climatic Research Unit, School of Environmental Sciences, University of East Anglia, Norwich, NR4 7TJ, UK \\ *Invited contribution by P. D. Jones, recipient of the Hans Oeschger Medal 2002.
}

Received: 14 January 2009 - Published in Clim. Past Discuss.: 24 February 2009

Revised: 15 June 2009 - Accepted: 19 June 2009 - Published: 25 June 2009

\begin{abstract}
The atmospheric circulation clearly has an important influence on variations in surface temperature and precipitation. In this study we illustrate the spatial patterns of variation that occur for the principal circulation patterns across Europe in the standard four seasons. We use an existing classification scheme of surface pressure patterns, with the aim of considering whether the patterns of influence of specific weather types have changed over the course of the 20th century. We consider whether the long-term warming across Europe is associated with more favourable weather types or related to warming within some of the weather types. The results indicate that the latter is occurring, but not all circulation types show warming. The study also illustrates that certain circulation types can lead to marked differences in temperature and/or precipitation for relatively closely positioned sites when the sites are located in areas of high relief or near coasts.
\end{abstract}

\section{Introduction}

The influence of the circulation on surface climate has been known by humans since the beginning of time. Since the advent of climatology these relationships have developed into circulation or weather types developed initially subjectively (e.g. Lamb, 1972 for the British Isles and Hess and Brezowsky, 1977 for Europe - the well know "Grosswetterlagen") but now objectively with a wide range of approaches and techniques (see reviews by Yarnal, 1993 and Huth et al., 2008). The derived weather types have been used in a wide

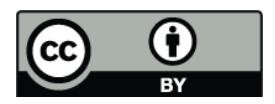

Correspondence to: P. D. Jones

(p.jones@uea.ac.uk) range of applications (see Yarnal, 1993 and Huth et al., 2008) in the field which is now called synoptic climatology.

With growing interest in climate change, many of the objective schemes are being used to study whether the climate is warming because of a greater frequency of 'warm' or less "cold" types or is the overall frequency of basic types relatively unchanged and most types are slightly warmer than they used to be. Two examples of this type of work are the studies undertaken by Osborn and Jones (2000) and van Oldenburgh and van Ulden (2003). In the first, the percentage of the season-to season variability of rainfall and temperature over Britain (using the England and Wales precipitation record, Alexander and Jones, 2001 and the Central England temperature record, Parker et al., 1992) that could be explained by three variables (flow direction and strength and vorticity, which together form the very simplest of objective weather typing) was estimated. The result was that the "weather" explained much of the high-frequency variability, but little in the way of longer (decadal and above) timescale variability. The second study looked at temperatures at De Bilt in the Netherlands and assessed whether 20th century temperature increases were specific to certain wind directions. The result was that temperatures increased for all wind directions except for those from the northeast during winter. Both results emphasize the warming, but highlight different aspects. Beck et al. (2007) also consider similar aspects, but only use monthly resolution data.

Here we extend these studies to the European scale and use continental-scale circulation typing approaches. Philipp et al. (2007) have developed a set of daily North Atlantic/European Circulation Types (CTs) covering the region $70^{\circ}$ to $25^{\circ} \mathrm{N}$ by $70^{\circ} \mathrm{W}$ to $50^{\circ} \mathrm{E}$ using a technique involving simulated annealing (a clustering algorithm). The analysis was based on the reconstructed daily mean sea-level pressure

Published by Copernicus Publications on behalf of the European Geosciences Union. 

seasonal analyses.

\begin{tabular}{lc}
\hline Season & Number of CTs \\
\hline DJF & 9 \\
MAM & 11 \\
JJA & 6 \\
SON & 8 \\
\hline
\end{tabular}

Table 1. Number of Circulation Types (CTs) for each of the four

and precipitation (drying in Southern Europe and increases in wetness in Northern Europe, see e.g. Fig. 3.14 of Trenberth et al., 2007) is a result of a change in the mix of CTs or is a result of within-type changes in the CTs. The daily surface network of temperature and precipitation data is discussed in Section 2. In Section 3, we briefly introduce the Philipp et al. (2007) method of deriving circulation types and illustrate how the surface temperature data are transformed into anomalies for the time of year. Section 4 discusses a selection of the results and Sect. 5 concludes.

\section{Data}

(MSLP) maps from Ansell et al. (2006) and used the full period of available data from 1850-2003. Different CTs were developed for each of the four standard seasons and also for the twelve sets of two-month seasons (JF, FM etc.).

At larger scales, it is certain that the circulation will explain less than it does on the scales of Britain or the Netherlands. This is because large-scale circulation typing is more complex than the simple objective typing (using flow direction and strength and vorticity) described above. Simpler typing is specific to relatively local scales as in the above two examples. Large-scale CTs consider the dominant atmospheric circulation patterns across the whole of Europe, hence are less influential at the local scale. A simple example of this is the influence of the North Atlantic Oscillation (NAO) on European temperature and precipitation patterns (e.g. Hurrell, 1995). The NAO (based for example on the normalized pressure difference between Gibraltar and Reykjavik) explains up to $40 \%$ of the variance of winter season (December to February) temperature variability in southern Scandinavia (Jones et al., 2003), yet if a more local pressure gradient were developed (for this location using, for example, pressure data from Berlin and Stockholm) the explained variance would be considerably higher. The explanatory variable is still essentially the same (the NAO), but in the more local case we are looking at the westerly wind strength specific to the region being considered (southern Scandinavia). The issue of local- versus regional-scale pressure gradients has been commented upon earlier (see Jacobeit et al., 2001 comparing the temperature variance explained by the NAO with a more local zonal index over Central Europe). The results have potential implications for statistical downscaling techniques that use CT-based schemes. Model biases in RCM-based scenarios (dynamic downscaling) are generally used as one of the reasons for developing statistical downscaling techniques, but the use of the simpler objective typing schemes will produce scenarios which are not spatially consistent between neighbouring regions. The use of large-scale CTs is one potential way of deriving spatially consistent scenarios across a much larger region.

Here, we will use the Philipp et al. (2007) CTs for the four standard seasons to look at their surface temperature and precipitation response. We wish to assess whether the longterm change in temperature over Europe (towards warming)
The EMULATE project developed a daily temperature (maximum and minimum) and precipitation database encompassing many of the available long-term records for the European continent (see extensive discussion of sources and quality control in Moberg et al., 2006). The quality control of the station database undertaken by Moberg et al. (2006) was extensive, with an emphasis on the extremes in each of the series, but there wasn't a thorough assessment of the long-term homogeneity of the records. The EMULATE series were bolstered by the addition of series developed for the European Climate Analysis and Dataset (ECA\&D, see Klok and Klein Tank, 2009). Here we chose those series that were as complete as possible for the period from 1911 to 2000 . We use series from Iceland and Portugal in the West to the Ural mountains in the East, so extending about $20^{\circ}$ further east than do the CTs from Philipp et al. (2007). The sites used show differences between the three variables and also for the periods of analysis. The locations of the available data used for the illustrated influences of each CT on surface climate will be evident in the subsequent figures.

\section{Methods}

Table 1 (from Philipp et al., 2007) gives the number of CTs for each of the four 3-month seasons. Figure 1 shows the percent of days in each season classified into each of the CTs for three periods (1911-1940, 1941-1970 and 1971-2000). The number of types in each season was determined by several objective criteria (see Philipp et al., 2007 for details). The ordering of the CTs was determined by the period 1850-2003, so there are differences between the three periods, slightly more so for winter and summer than for the transition seasons. Also in all seasons except spring, the 1971-2000 period differs more from the two earlier periods. All days are classified into one of the types, and readers should be mindful of this when assessing the results. Obviously for a given $\mathrm{CT}$, there will be some days that would be very close to the basic type (referred to by Phillipp et al., 2007 as the centroid pattern), while for others the CT to which they are assigned is the closest of all the possible CTs. In these latter 

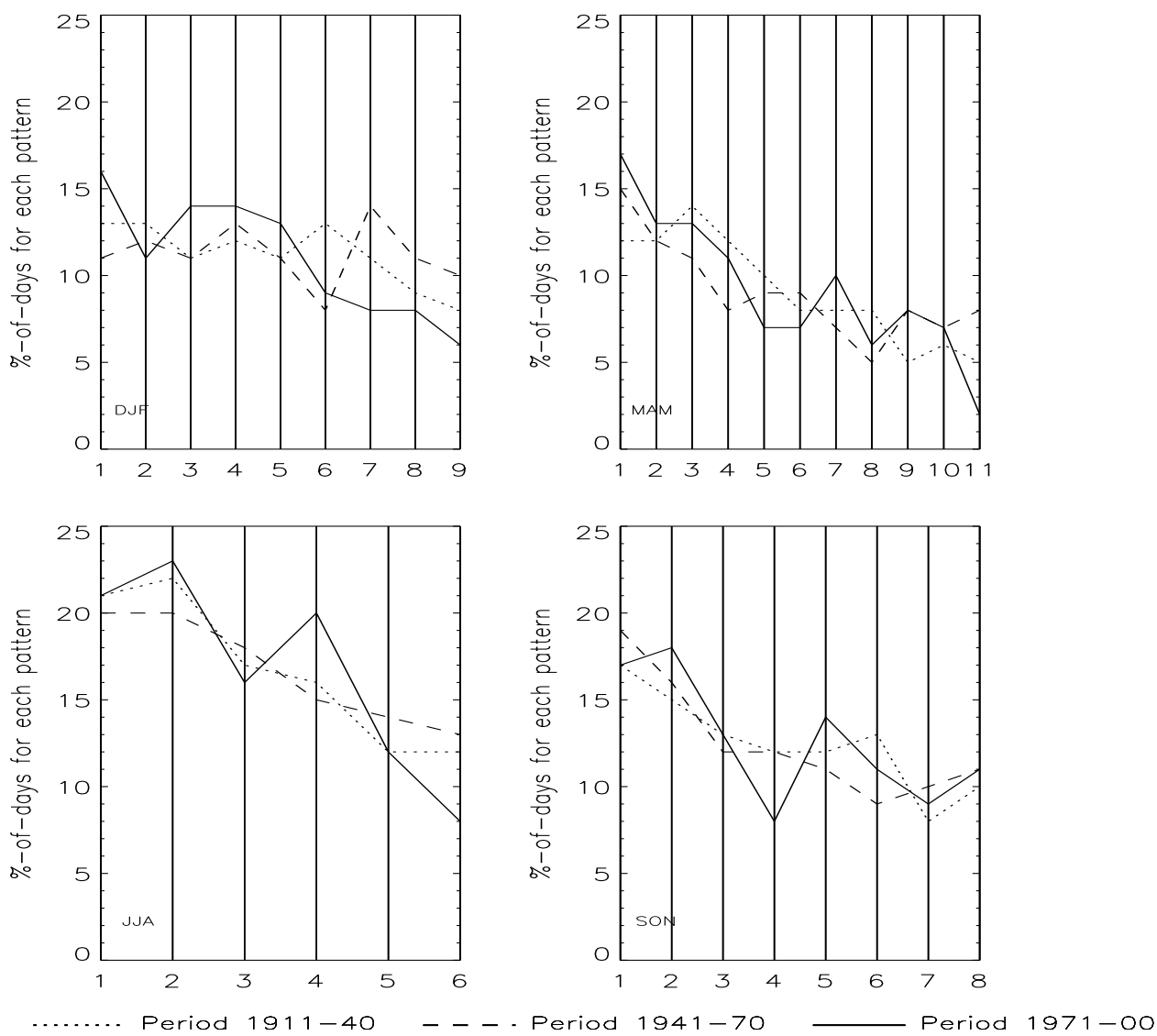

Fig. 1. The percentage of days of each CT within each season. The different line styles show these proportions for each of the three periods (1911-1940, 1941-1970 and 1971-2000). Each day within each season is classified into one of the types for each season, so the sum of the percentages for each period will be $100 \%$.

cases, the surface climate response may be somewhat different from the types which look more like the basic pattern for each CT. Forcing all days into one of the basic types dilutes the patterns compared to the "continuous" nature of typing with the simplified (but necessarily more local) techniques discussed earlier. We use the word "continuous" as in the simpler typing schemes (e.g. Osborn et al., 2000) days are categorised according to three continuous variables (flow strength, wind direction and vorticity). Another possibility would be to weight each day by the correlation of that day's pattern compared with the 'average' pattern for that CT. We do not investigate this or the issue of differences within types further, but instead treat days of one CT type equal, looking at the average spatial response of surface temperature and precipitation to the particular CT. Later, we will consider whether the response to particular CTs changes during the period from 1911 to 2000 .

To assess the surface response to each of these CTs, we constructed maps showing the effects on mean temperature, the diurnal temperature range (DTR) and precipitation. As the mean temperature and DTR response will be impacted by the time of year (particularly during the transition seasons), we extracted an annual cycle for each day of the year based on the 1961-1990 period for each station. This was developed separately for maximum and minimum temperature by smoothing the 1961-1990 average (where the raw average was based on the 30 January 1sts, 30 January 2nds, etc). The smoothing used an 11-term binomial filter, which has been recommended by a number of studies (Jones et al., 1999; Horton et al., 2000) as being sufficient to smooth the daily averages from only 30 observations, whilst still leaving a number of important singularities (Lamb, 1950) evident in many regions of Europe. Figure 2 shows an example of the filter for Kiev, a station chosen at random from the almost 200 possibilities. Daily temperature and DTR anomalies were then computed from the smoothed station-specific curves. The same procedure with smoothing was used for precipitation, but this essentially gives each smoothed daily value the 1961-1990 average daily precipitation amount (i.e. the monthly total divided by the number of days in the month). 


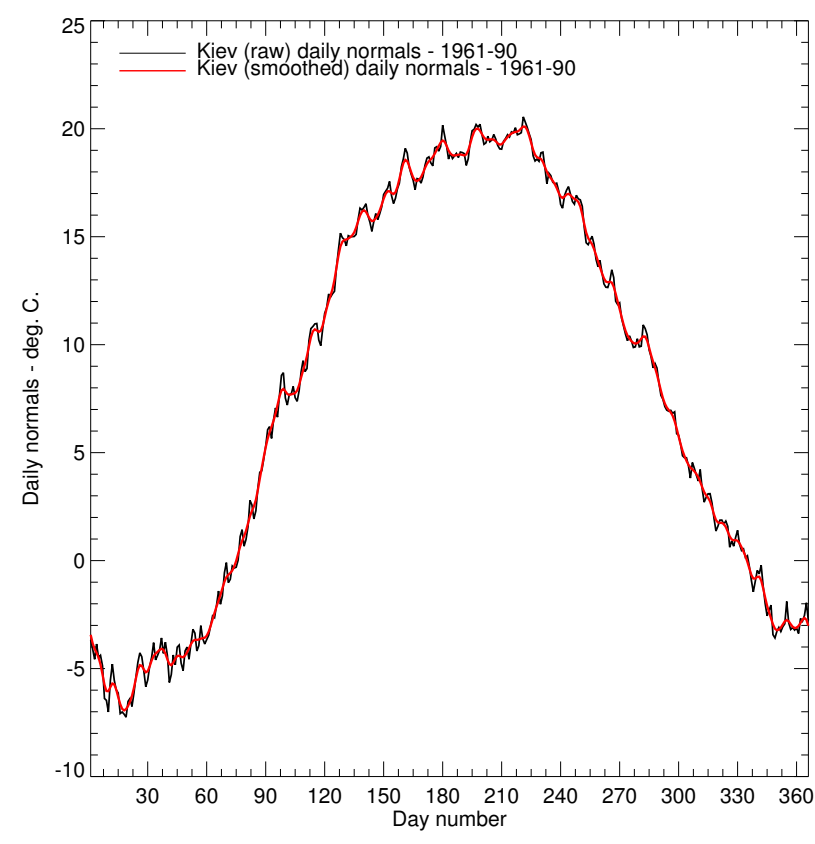

Fig. 2. Example of the daily filter for mean temperature for the station at Kiev.

As the daily station temperature and precipitation data are most complete for the period from the early 20th century, three 30-year periods (1911-1940, 1941-1970 and 19712000) were chosen for the analysis. Availability of data still means that there are more series that can be used for the later two 30-year periods compared to the first. For mean temperature, there are 150, 185 and 210 stations for each of the three 30 -year periods respectively. Counts are slightly different for precipitation and DTR.

To assess the significance of the departures for temperature, DTR and precipitation, a Monte Carlo procedure was used. In this analysis a distribution for each station was calculated by randomly sampling all days in each season 10000 times and then compared with the actual value based on the $\mathrm{N}$ days of each $\mathrm{CT}$, enabling the statistical significance for each station to be assigned for each CT pattern. In the latter figures, the 95\% statistical significance level was used.

\section{Results}

Thirty four different sets of figures were produced for each of the three 30-year periods. These include maps for each of the types in Table 1 . Here we can show only a very small selection, but summarise the results in a single figure for each of the four seasons. We emphasize the results from the extreme seasons, as they are less affected by the changes in the influence of the circulation that occur during the transition seasons. The use of anomalies from the average 19611990 annual cycle (particularly for mean temperature) does ameliorate the issue to some extent, but simple examples for some of the patterns shows that some consistently bring warm extremes in May, but cooler than normal temperatures during March. This doesn't happen during the extreme seasons, but is also prevalent in the autumn. It would be ameliorated still further using the two-season CTs from Philipp et al. (2007), but would still be noticeable for some adjacent months (e.g. October and November). It might be possible to undertake the analyses on individual months, but this doesn't overcome the issue of some CTs in some seasons being more dominant during the early or latter months within the season. We don't investigate this further, but it would be important to do so for smaller sub-regions of Europe.

We now show three examples of the CTs, one each for the summer, autumn and spring season. We discuss each in turn and then make some overall comments about the maps, including the 31 that haven't been shown. The full set of 34 circulation patterns and surface responses is included in the Supplementary Information (http://www.cru. uea.ac.uk/projects/emulate-ct/). These comments relate to issues of relatively close stations sometimes giving opposite responses, particularly for DTR.

Figure 3 shows CT1 for the summer season and the response of mean surface temperature, DTR and precipitation amount for the period 1911-1940. In the figure we distinguish between the locations where the anomalies of the three variables are positive and negative and where the deviations are statistically significant at the $95 \%$ level using the Monte Carlo procedure detailed earlier. This $\mathrm{CT}$ is the classic pattern of an "Azores" high extending NE towards Europe. As expected this gives less precipitation over much of western Europe together with warmer than average temperatures and an enhanced DTR. Over most of the site locations in western Europe the response for these types of CT days is significant. Over eastern Europe, the patterns are weaker and less significant. The response patterns vary little for the two latter periods (1941-1970 and 1971-2000, not shown, but see Supplementary Information).

Figure 4 shows CT4 for the spring season (for 1971-2000) and the response patterns for the same three variables as in Fig. 3. This CT involves a relatively deep low (for the time of year) over southern Scandinavia, giving anomalous northwesterly flow over western Europe and anomalous southwesterly flow further east. As expected mean temperatures are cooler than normal over all of western Europe with a reduced DTR. Further east temperatures are warmer than normal with enhanced DTRs over southeastern Europe. Precipitation amounts are greater than normal in central and western Europe and reduced around the peripheries of Europe (Iberia, the Balkans, northeastern Europe and northern Scandinavia). This response pattern is similar for the two earlier periods of 1911-1940 and 1941-1970 (see Supplementary Information).

Figure 5 incorporates CT3 for autumn (for 1941-1970) and its response patterns as in Fig. 3. This CT shows an 

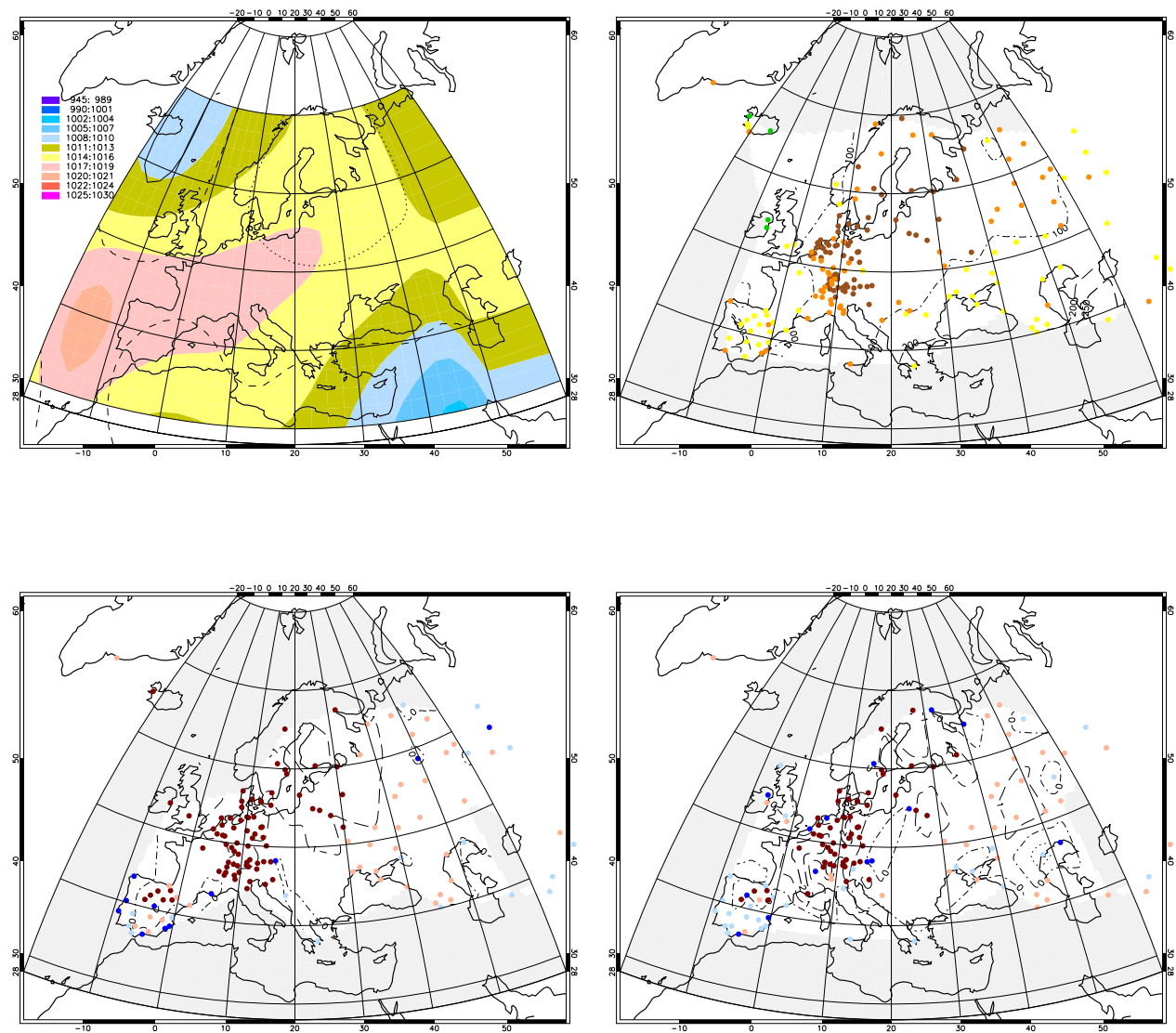

Fig. 3. Response of European surface temperatures, DTR and precipitation to CT1 for Summer (1911-1940). The top left panel shows the absolute MSLP values for the CT (coloured) with the anomaly from 1961-1990 shown by the contour lines. Dotted/solid lines are positive/negative anomalies at $2 \mathrm{hPa}$ intervals. The dashed line shows the zero anomaly. The top right panel shows the precipitation response to days of the CT. Yellow/orange dots indicate above/below normal precipitation, while green/brown indicate statistically significant (95\% level) above/below normal precipitation. The bottom two panels are for mean temperature (left) and DTR (right). Here above/below normal temperatures and DTR are indicated by pink/light blue dots, while statistically significant departures are given in red/dark blue. Contour intervals for mean temperature and DTR are dashed lines (positive) and dotted lines (negative) and the zero line is dash/dot. For precipitation, above normal values $(200 \%)$ are dashed while below normal values (50\%) are dotted, with normal (100\%) dash/dot. Grey shaded areas are outside the range of the stations.

anomalous and deep low centred over the Gulf of Finland together with higher than normal pressures over the Atlantic Ocean west of Ireland. This pattern would bring enhanced northerlies over western Europe and enhanced southerlies over the Ukraine and western Russia. As expected then, mean temperatures are reduced in western Europe from Scandinavia to the northwestern Mediterranean, while they are enhanced from the Black Sea northwards and eastwards. The response patterns are a little different for DTR and precipitation. For this CT the response patterns are similar but inverse for these two variables, showing the relationship that is linked to more clouds (so higher precipitation) and vice versa. DTR is reduced over central Europe encompassing the Low Countries, Germany, Poland and the Baltic States. Precipitation is increased over this same region, but the area with significantly increased precipitation extends further east into western Russia. DTR is enhanced around the Mediterranean, Black and Caspian Sea regions. Precipitation is reduced over the British Isles, western France, Iberia and much of the region around the Mediterranean, Black and Caspian Seas. This pattern is similar in the other two periods (19111940 and 1941-1970, not shown, but see Supplementary Information).

Figures 3-5 are just a small percentage of the plots produced in this study (see full set in the Supplementary Information). They show that for the three CTs illustrated, very similar patterns of mean temperature, DTR and precipitation occurred in all three periods. Next we discuss a number of the small-scale features evident on many of the maps. In the figures shown there are a number of instances where closely located sites respond differently in the mean temperature, DTR or precipitation maps. More closely-located 

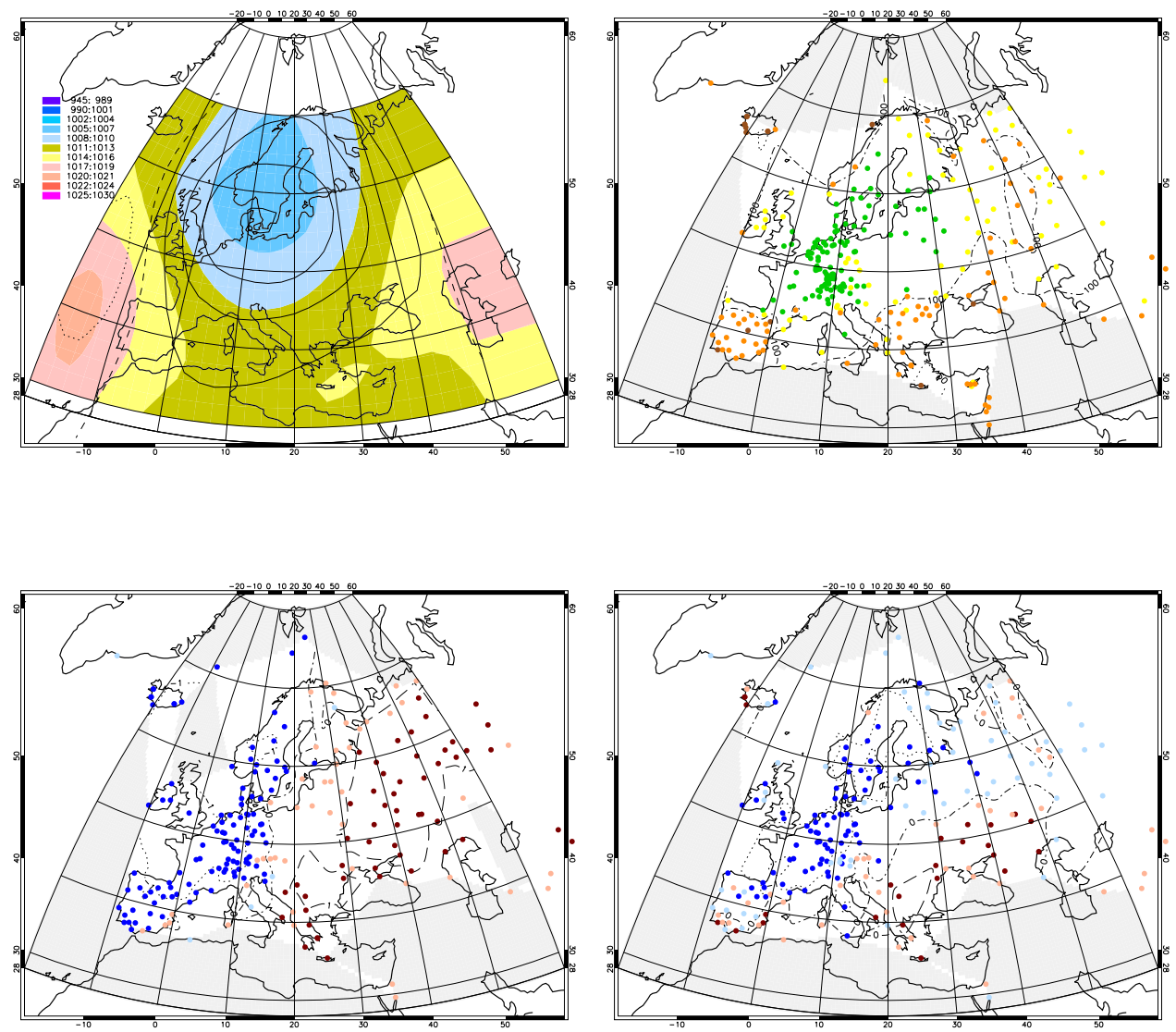

Fig. 4. As Fig. 3 but for Spring CT4 for 1971-2000.

sites respond differently in the DTR maps compared to those for mean temperature and precipitation. This is initially suggestive of homogeneity issues at some sites. It is extremely difficult to ensure good homogeneity of daily maximum and minimum temperature records, and hence DTR. Most aspects that cause discontinuities in temperature records will affect maximum and minimum temperature differently, so will cancel when mean temperature is considered, but the effect will be amplified in DTR. Although homogeneity for DTR may be an issue in some cases, there are numerous examples where the closely-located sites respond differently in all three 30 -year periods. The sites are often located, (1) on the coast with the neighbouring site more inland; (2) markedly different elevations within mountain regions and; (3) being located on different sides of major mountain ranges (particularly the Alps). Depending on the wind directions associated with the CTs there can be marked differences either side of mountains (see Fig. 5 for precipitation and DTR), which clearly relate to windward and leeward sides and rain shadows. Away from major highland areas (e.g. the North European Plain) the responses of the sites tend to have hardly any closely-located sites responding differently.
We now return to the two questions posed in the introductory sections. These were (1) do the response patterns to the various CTs change between the three periods 1911-1940, 1941-1970 and 1971-2000 and (2) do the CTs explain any of the longer timescale variance of average temperature change across the large region studied? We address the first question by counting the number of positive and negative and then significantly positive/negative responses at the sites across Europe. We express these counts as percentages as the number of available sites across Europe differs (see earlier) for the three periods and is also different between variables.

Figure 6 shows summary diagrams for the four seasons. We show these plots for the three variables (precipitation, mean temperature and DTR). These plots present a lot of information. The top panels (for precipitation) for each season show which patterns generally bring wetter and which drier conditions to the greater European region. The middle and lower panels (for mean temperature and DTR respectively) show similar information for warmth or coldness across the large region. We begin by discussing the precipitation panels first, beginning with winter. Averaged over Europe, we can see which CTs give significantly above normal precipitation (CTs 4 and 5) at more than half the sites (in at least one of the 

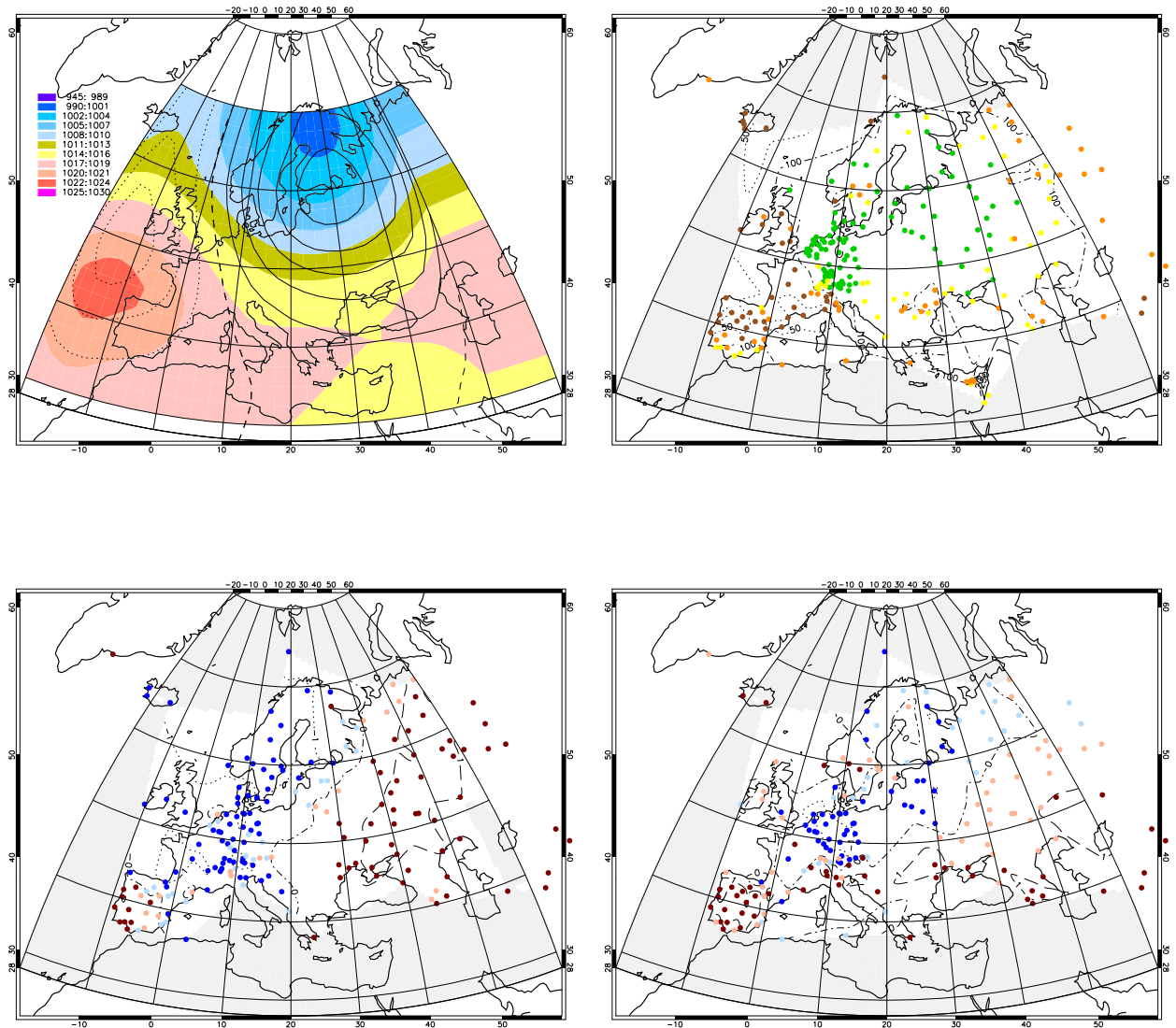

Fig. 5. As Fig. 3 but for Autumn CT3 for 1941-1970.

periods) and which give significantly below normal (CTs 2 , 3 , and 6). For the three periods, however, there is little difference in the percentage of significantly positive/negative sites between the three periods. For spring, the dominant wet pattern is CT 4, with CT 6 dominantly dry. For summer, there are no dominant wet or dry patterns. For autumn, the dominant wet pattern is $\mathrm{CT} 6$, with the dominant dry pattern being CT 4. For all three seasons as with winter, there is little difference between the three periods.

For the mean temperature panel, for all four seasons, there are more patterns (as expected) which are dominantly cool or warm than evident for precipitation (so affecting at least half the sites, in one of the periods, across the large European region). For winter, there are four dominant warm patterns (CTs 1, 4, 5 and 9) and three which are dominantly cool (CTs 2, 7 and 8). For spring, there are two dominant warm patterns (CTs 7 and 10) with two dominant cool patterns (CTs 1 and 4). For summer, CT1 is a dominant warm pattern and CT2 cool. For autumn, CTs 5 and 6 are dominantly warm and CTs 4 and 7 cool. Unlike precipitation though, the solid lines (for the 1971-2000 period) tend to be slightly above those (indicating warming) for the other periods for many of the CTs in all seasons except autumn. This is clearer for the black lines, whereby we distinguish positive from negative departures. For DTR, there are no dominant patterns with the closest to our significance criterion (more than half the stations significant with the same sign of departure) being CT1 in summer.

For the precipitation and DTR panels in comparison to the mean temperature panels, there is a greater spread of the red, black and blue lines. This implies that there are a large number of stations (25-50\% depending on the CT) where there is either more or less precipitation/DTR, but the amount isn't significant. For the mean temperature panel in winter the spread is smaller with only $10-20 \%$ of stations for all CTs not having statistically significant anomalies for each CT. This spread is wider for the other seasons for mean temperature, slightly larger for summer compared to spring and autumn. This shows that patterns of mean temperature departures are more organized than for precipitation and DTR, especially so in winter compared to summer. This is evident from the number of patterns which are dominated by one sign of the temperature or precipitation anomaly.

The second question has already been partly addressed for mean temperature by Philipp et al. (2007) in their Fig. 9. In this they compare observed changes in temperature for all four seasons over the central part of our domain (Central Europe, $45-55^{\circ} \mathrm{N}$ by $5-20^{\circ} \mathrm{E}$ ) with estimates of changes from 

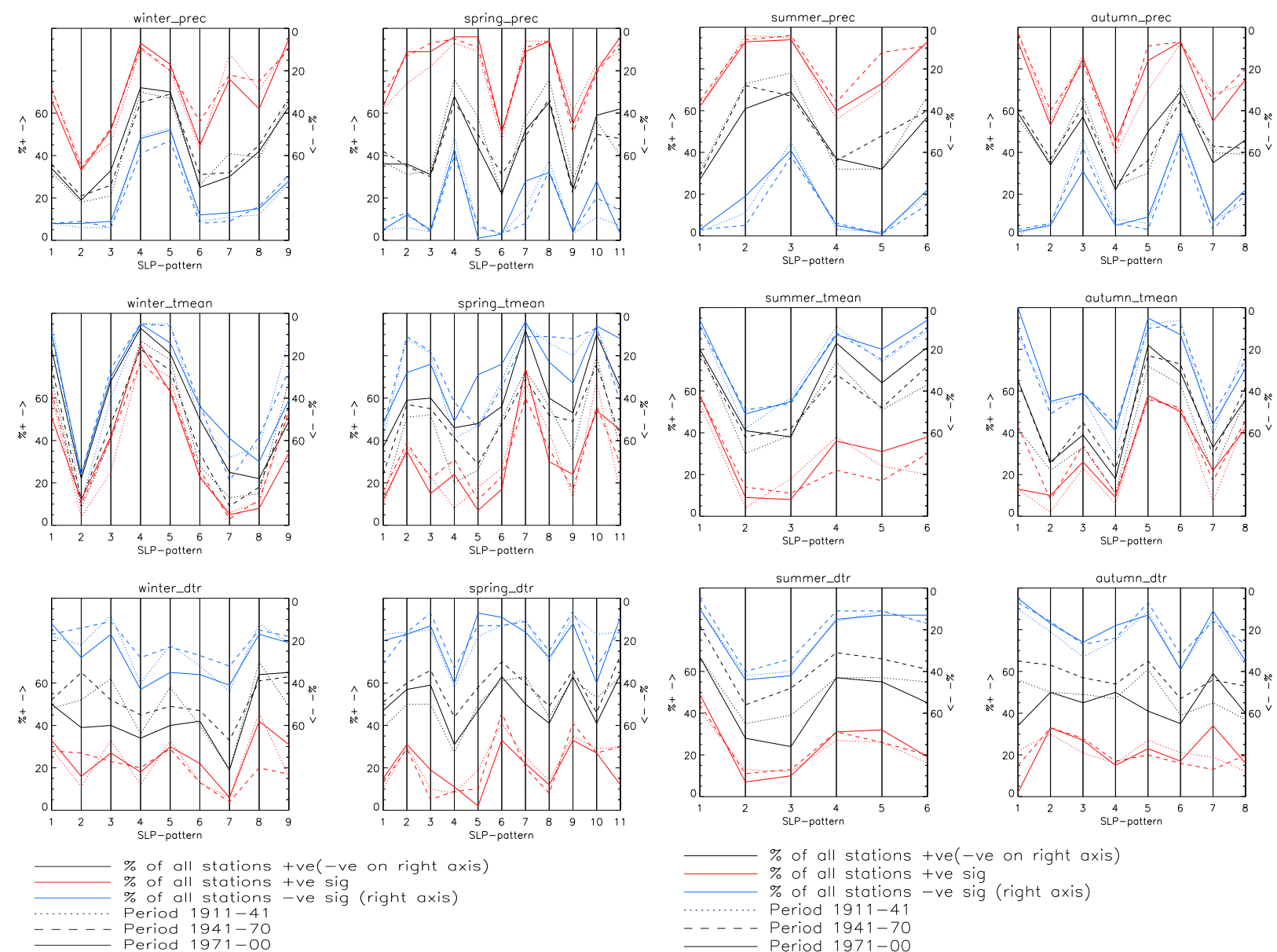

Fig. 6. Summary plots of the overall response of precipitation, surface temperature and DTR for each of the three periods (1911-1940, 1941-1970 and 1971-2000). Winter and Spring are on the left side, with Summer and Autumn on the right. The plots show the percent of stations with positive (warm/greater for mean temperature/DTR, left axis) and negative (cold/lesser for mean temperature/DTR, right axis) anomalies for the three periods (shown by different line styles). For precipitation the red/blue is reversed, so red indicates drier than normal and blue wetter than normal. The red/blue lines indicate the percentage of stations with statistically significant departures in the same three line styles.

regression against the counts of the various CTs in each of the seasons. In all seasons, though, the circulation explains much of the high-frequency temperature variance, implying that the underlying warming would be more statistically significant if the circulation component were extracted. Only in spring (95\%) and autumn (90\%) did the trend of the circulation component of temperature increase over their study period (1851/2000-2003). Circulation-related temperature trends in spring and summer are slightly negative. This finding is in agreement with Osborn and Jones (2000) and van Oldenburgh and van Ulden (2003), so we don't pursue this any further.

\section{Conclusions}

The aims of this paper have been to look at the possible changing influence of the atmospheric circulation on surface temperature, precipitation and DTR across Greater Europe. We use the recently developed classification scheme from Philipp et al. (2007) which reduces daily surface pressure maps into 6 to 11 patterns depending on the season. For surface temperature and precipitation data we use long daily series (extending from 1911-2000) developed during the EMULATE and ECA\&D projects. We reduce all station series to anomalies from a specifically developed annual cycle for each station. For each of the 34 CTs (grouping all four seasons together) we plot anomaly maps of mean temperature, DTR and precipitation for all days of each CT within the three periods, 1911-40, 1941-70 and 1971-2000. We assess the significance of the average maps using Monte Carlo procedures.

The results reveal that across Greater Europe there are dominant warm and cold patterns for temperature, where more than half the station locations show significantly 
positive or negative departures. Fewer CTs could be described as dominantly wet or dry when it came to precipitation and even fewer with dominantly high or low DTR. Finally, we addressed the question of whether the circulation influence of these CTs has changed during the three periods. For mean temperature, particularly for winter and to a lesser extent spring and summer, there was evidence of more of the CTs indicating warmer temperatures during the most recent period. For precipitation and DTR, and also mean temperatures in autumn, there was less evidence of changes occurring between the three periods.

Acknowledgements. This work has been supported by the U.S. Department of Energy (grant DE-FG02-98ER62601). The authors also acknowledge support from the EU-EMULATE project (EVK2CT-2002-00161) which developed the circulation typing scheme and the daily station dataset of temperature and precipitation data. Jucundus Jacobeit and one anonymous reviewer significantly improved the manuscript during the review process.

Edited by: V. Masson-Delmotte

Reviewed by: H. Wanner, J. Jacobeit, and P. Yiou

\section{References}

Alexander, L. V. and Jones, P. D.: Updated precipitation series for the United Kingdom, Atmos. Sci. Lett., 1, 142-150, 2001.

Ansell, T. J., Jones, P. D., Allan, R. J., Lister, D., Parker, D. E., Brunet, M., Moberg, A., Jacobeit, J., Brohan, P., Rayner, N. A., Aguilar, E., Alexandersson, H., Barriendos, M., Brandsma, T., Cox, N. J., Della-Marta, P. M., Drebs, A., Founda, D., Gerstengarbe, F., Hickey, K., Jonsson, T., Luterbacher, J., Nordli, A., Oesterle, H., Petrakis, M., Philipp, A., Rodwell, M. J., Saladie, O., Sigro, J., Slonosky, V., Srnec, L., Swail, V., GarciaSuarez, A. M., Tuomenvirta, H., Wang, X., Wanner, H., Werner, P., Wheeler, D., and Xoplaki, E.: Daily mean sea level pressure reconstructions for the European - North Atlantic region for the period 1850-2003, J. Climate, 19, 2717-2742, 2006.

Beck, C., Jacobeit, J., and Jones, P. D.: Frequency and within-type variations of large-scale circulation types and their effects on low-frequency climate variability in Central Europe since 1780, Int. J. Climatol., 27, 473-491, 2007.

Hess, P. and Brezowsky, H.: Katalog der Grossweterlagen Europas 1881-1976. 3e verbesserte und ergänzie Auflage, Berichte des Deutschen Wetterdienstes 113, Offenbach, Germany, 70 pp., 1977.

Hurrell, J. W.: Decadal trends in the North Atlantic Oscillation: regional temperatures and precipitation, Science, 269, 676-679, 1995.

Huth, R., Beck, C., Phillipp, A., Demuzere, M., Ustrnul,Z., Cahynová, M., Kyselý, J., and Tveito, O.-E.: Classifications of atmospheric circulation patterns: recent advances and applications, Annals of the New York Academy of Sciences, 1146, 105$152,2008$.

Jacobeit, J., Jönsson, P., Bärring, L., Beck, C., and Ekström, M.: Zonal indices for Europe 1780-1995 and running correlations with temperature, Clim. Change, 48, 219-241, 2001.
Jones, P. D., Horton, E. B., Folland, C. K., Hulme, M., and Parker, D. E.: The use of indices to identify changes in climatic extremes, Clim. Change, 42, 131-149, 1999.

Jones, P. D., Osborn, T. J., and Briffa, K. R.: Pressure-based measures of the NAO: A comparison and an assessment of changes in the strength of the NAO and in its influence on surface climate parameters, in: North Atlantic Oscillation, edited by: Hurrell, J. W., Kushnir, Y., Ottersen, G., and Visbeck, M., American Geophysical Union, Washington DC, 51-62, 2003.

Klok, L. and Klein Tank, A. M. G.: Updated and extended European dataset of daily climate observations, Int. J. Climatol., 29, 1182-1191, 2009.

Lamb, H. H.: Types and spells of weather around the year in the British Isles, Quart. J. Roy. Meteor. Soc., 76, 393-438, 1950.

Lamb, H. H.: British Isles weather types and a register of the daily sequence of circulation patterns, 1861-1971. Geophysical Memoir, 116, HMSO, London, 85 pp., 1972.

Moberg, A., Jones, P. D., Lister, D. H., Walther, A., Brunet, M., Jacobeit, J., Alexander, L. V., Della-Marta, P. M., Luterbacher, J., Yiou, P., Chen, D., Klein-Tank, A. M. G., Saladié, O., Sigró, J., Aguilar, E., Alexandersson, H., Almarza, C., Auer, I., Barriendos, M., Begert, M., Bergström, H., Böhm, R., Butler, C.J., Caesar, J., Drebs, A., Founda, D., Gerstengarbe, F.W., Micela, G., Maugeri, M., Öesterle, H., Pandzic, K., Petrakis, M., Srnec, L., Tolasz, R., Tuomenvirta, H., Werner, P. C., Linderholm, H., Philipp, A., Wanner, H., and Xoplaki, E.: Indices for daily temperature and precipitation extremes in Europe analyzed for the period 1901-2000, J. Geophys. Res., 111, D22106, doi:10.1029/2006/JD007103, 2006.

Osborn, T. J. and Jones, P. D.: Air flow influences on local climate: observed United Kingdom climate variations, Atmos. Sci. Lett., 1, 62-74, 2000.

Parker, D. E., Legg, T. P., and Folland, C. K.: A new daily Central England temperature series, 1772-1991, Int. J. Climatol., 12, 317-342, 1992.

Philipp, A., Della-Marta, P. M., Jacobeit, J., Fereday, D. R., Jones, P. D., Moberg, A., and Wanner, H.: Long-term variability of daily North Atlantic-European pressure patterns since 1850 classified by simulated annealing clustering, J. Climate, 20, 4065-4095, 2007.

Trenberth, K. E., Jones, P. D., Ambenje, P., Bojariu, R., Easterling, D., Klein Tank, A., Parker, D., Rahimzadeh, F., Renwick, J. A., Rusticucci, M., Soden, B., and Zhai, P.: Observations: Surface and Atmospheric Climate Change, in: Climate Change 2007: The Physical Science Basis, Contribution of Working Group 1 to the Fourth Assessment Report of the Intergovernmental Panel on Climate Change, edited by: Solomon, S., Qin, D., Manning, M., Chen, Z., Marquis, M., Averyt, K. B., Tignor M., and Miller, H. L., 235-336, Cambridge University Press, Cambridge, United Kingdom and New York, NY, USA, 2007.

van Oldenborgh, G. J. and van Ulden, A.: On the relationship between global warming, local warming in the Netherlands and changes in the circulation in the 20th century, Int J. Climatol., 23, 1711-1724, 2003.

Yarnal, B.: Synoptic climatology in environmental analysis, Belhaven Press: London, 1993. 